\title{
Práticas dos profissionais das equipes de saúde da família voltadas para as mulheres em situação de violência sexual*
}

\author{
HEALTH FAMILY PROFESSIONALS' PRACTICES TOWARD WOMEN \\ IN SEXUAL VIOLENCE SITUATIONS
}

\begin{abstract}
PRÁCTICAS DE PROFESIONALES DE LOS EQUIPOS DE SALUD DE LA FAMILIA DIRIGIDAS A LAS MUJERES EN SITUACIÓN DE VIOLENCIA SEXUAL
\end{abstract}

Celin Camilo de Oliveira', Rosa Maria Godoy Serpa da Fonseca"

\section{RESUMO}

Este trabalho apresenta os resultados de uma pesquisa desenvolvida com profissionais que atuam no Programa de Saúde da Família - PSF no Estado de Minas Gerais. $\mathrm{O}$ objetivo foi analisar as práticas destes profissionais voltadas para mulheres em situação de violência sexual. Os dados foram coletados em uma Oficina de Trabalho tendo como suporte teórico para a análise as categorias gênero e violência de gênero. Constatou-se que a violência sexual contra a mulher envolve questões nas dimensões singular, particular e estrutural da realidade objetiva, que merecem ser refletidas pelos profissionais de saúde. $\mathrm{O}$ atendimento às mulheres em situação de violência sexual só poderá ser eficaz à medida que houver um trabalho intersetorial, com políticas públicas claras e eficazes e com o adequado preparo dos profissionais de saúde.

\section{DESCRITORES}

Saúde da família.

Assistência à saúde.

Violência contra a mulher.

Identidade de gênero.

\section{ABSTRACT}

This study presents the results of a qualitative survey carried out with professionals working in the Health Family Program in the State of Minas Gerais. It aimed at analyzing Health Family teams' professional practices with women submitted to situations of sexual violence. The data were collected in a workshop, having as theoretical support for analysis both the categories gender and gender violence. It was verified that sexual violence against women involves several questions on the singular, particular and structural levels of reality, something that health professionals must think about. Caring for women in sexual violence situations will only be effective if various sectors work together, with clear, efficient public policies and adequately trained health professionals.

\section{KEY WORDS}

Family health.

Delivery of health care.

Violence against women.

Gender identy.

\section{RESUMEN}

Este trabajo presenta los resultados de una pesquisa desarrollada con profesionales que actúan en el Programa de Salud de la Familia - PSF en el Estado de Minas Gerais. El objetivo fue analizar las prácticas de estos profesionales volcadas para las mujeres en situación de violencia sexual. Los datos fueron colectados en una Oficina de Trabajo teniendo como suporte teórico para la análisis las categorías genero y violencia de genero. Se constató que la violencia sexual contra la mujer envuelve cuestiones en las dimensiones singular, particular y estructural de la realidad objetiva que merecen ser reflejadas por los profesionales de salud. El atendimiento a las mujeres en situación de violencia sexual sólo podrá ser eficaz a la medida que haya un trabajo intersectorial, con políticas públicas claras y eficaces y con el adecuado preparo de los profesionales de salud.

\section{DESCRIPTORES}

Salud de la familia.

Prestación de atención de salud. Violencia contra la mujer.

Identidad de género.

\footnotetext{
Extraído da tese "Prática dos profissionais das equipes de saúde da família voltadas para as mulheres em situação de violência sexual: uma abordagem de gênero", Escola de Enfermagem, Universidade de São Paulo, 2005.

I Doutora em Enfermagem pela Escola de Enfermagem, Universidade de São Paulo (EEUSP), São Paulo, SP, Brasil. celinacamilo@ gmail.com

II Professora Titular do Departamento de Enfermagem em Saúde Coletiva da Escola de Enfermagem, Universidade de São Paulo (EEUSP), São Paulo, SP, Brasil. Coordenadora da Coordenadoria de Assistência Social (COSEAS) da Universidade de São Paulo (USP), São Paulo, SP, Brasil. rmgsfon@usp.br
} 


\section{INTRODUÇÃO}

A violência sexual contra a mulher tem sido foco de diferentes debates e estudos buscando discutir a magnitude global do problema. Existe na sociedade como uma questão universal que atinge mulheres de todas as classes sociais, etnias, religiões, idades e com níveis de escolaridade diversos. Foi guindada como uma questão internacional quando, em 1993, a Assembléia Geral das Nações Unidas adotou a Declaração para Eliminação da Violência contra as Mulheres. Posteriormente, em 2002, a Organização Mundial de Saúde, mediante o Relatório Mundial sobre Violência e Saúde, definiu a violência sexual contra a mulher como um dos problemas da saúde de prevalência e incidência importantes e alertou para a insuficiência de estudos, dados e informações que permitam estimar a dimensão e extensão do problema. Apesar de, na maioria dos países, haver pouca pesquisa sobre o tema, os dados disponíveis sugerem que quase uma em quatro mulheres no mundo, pode vivenciar a violência perpetrada por um parceiro íntimo e quase um terço das adolescentes relatam que sua primeira experiência sexual foi forçada. Os dados sobre violência sexual geralmente são fornecidos pela polícia, clínicas, organizações não-governamentais e algumas pesquisas de universidades.

A relação entre essas fontes e a magnitude global do problema da violência sexual contra a mulher equivale a um iceberg; ou seja, a gravidade do problema ainda está submersa ${ }^{(1)}$.

Existe autora $^{(2)}$ que refere haver uma conspiração do silêncio que cerca a violência sexual, o que impede que os dados quantitativos e qualitativos possam melhor revelar a magnitude desse problema.

Pesquisa nacional realizada nos Estados Unidos relata que $14,8 \%$ das mulheres com mais de 17 anos de idade relataram terem sido estupradas; mais $2,8 \%$ passaram por tentativa de estupro e $0,3 \%$ da amostra relatou ter sido estuprada no ano anterior. Quanto à forma de violência sexual contra a mulher em todo o mundo, a mais comum é aquela perpetrada por um parceiro íntimo, concluindo que a vulnerabilidade da mulher à agressão sexual é ampliada entre as mulheres casadas ou que vivem com um parceiro ${ }^{(1)}$.

No que tange à disponibilidade de dados sobre causa mortis ressalte-se, porém, que a violência sexual contra a mulher nem sempre está formal e linearmente vinculada à determinação da morte, até porque os traumatismos físicos e psíquicos provocados pela violência, bem como suas conseqüências, não são suficientemente reconhecidos, diagnosticados e $\operatorname{tratados}^{(3)}$.
Há, sem dúvida, um muro de silêncio em torno do assunto, no qual sempre se coloca em dúvida a palavra da mulher que sofre violência sexual. Tal situação induz a que apenas $10 \%$ dos casos cheguem às Delegacias de Polícia ${ }^{(4)}$.

Pesquisa da Sociedade Mundial de Vitimologia da Holanda sobre violência doméstica contra a mulher (em um universo de 138 mil mulheres de 54 países), entre outros, foram encontrados, para o caso do Brasil, os seguintes dados: $23 \%$ das mulheres brasileiras estão sujeitas à violência doméstica; a cada minuto, uma mulher é agredida em seu próprio lar por uma pessoa com quem mantém relação de afeto; as estatísticas disponíveis e os registros nas delegacias especializadas de crimes contra a mulher demonstram que $70 \%$ dos casos acontecem dentro de casa e que o agressor é o próprio marido ou companheiro ${ }^{(5)}$.

Considerando-se que o Programa de Saúde da Família (PSF) pretende ser uma reorientação do modelo asistencial em saúde, é fundamental estudar o quanto as equipes estão preparadas para o enfrentamento da violência sexual nos seus territórios de ação. Para tanto, urge conhecer as concepções e o estado atual das práticas que ora são desenvolvidas. Diante disso, este estudo teve o objetivo de identificar e analisar as práticas dos profissionais das equipes de Saúde da Família com mulheres em situação de violência sexual.

\section{MÉTODO}

Foi um estudo de caráter qualitativo que se propôs a indagar uma realidade específica com uma carga histórica que de afeto. reflete posições frente à realidade, momentos do desenvolvimento e da dinâmica social, preocupações e interesses de classes e de grupos determinados ${ }^{(6)}$.

A análise dos dados teve como suporte teórico principal a categoria gênero e violência de gênero, pois a violência sexual contra a mulher foi entendida como uma manifestação das relações de poder historicamente desiguais, estabelecidas entre homens e mulheres. Tem, portanto, no componente cultural o seu grande sustentáculo e fator de perpetração $^{(7)}$.

\section{O conceito de gênero surgiu}

na década de 80, nos estudos feministas para compreender as relações estabelecidas entre mulheres e homens, referindo-se ao sexo social e historicamente construído(8).

A definição de gênero como categoria de análise foi trabalhada no início da década de 80 , pela historiadora norteamericana Joan Scott. Gênero foi 
um termo proposto por aquelas que defendiam que a pesquisa sobre mulheres transformaria fundamentalmente os paradigmas no seio de cada disciplina ${ }^{(9)}$.

Gênero pode ser proposto como

uma categoria de análise, conceituando-o como elemento constitutivo das relações sociais, baseado nas diferenças percebidas entre os sexos e como uma forma primeira de significar as relações de poder ${ }^{(9)}$.

Reconhecida esta categoria há redefinição e ampliação das noções antigas e espaço para incluir a experiência pessoal e subjetiva. Portanto,

a proposta não é apenas para escrever uma nova história para as mulheres, mas é algo muito mais abrangente, pois permite a reescrita de uma nova história para mulheres e homens $^{(9)}$

Violência de gênero é considerada aquela que contém, em si, características próprias e que acontecem com a mulher simplesmente pelo fato de ser mulher. É uma violência que tem locais próprios, forma de acontecer característica, condução e perpetração que ocorrem por uma relação marcada pela dominação masculina. As raízes da violência encontram-se nas próprias relações de gênero. Mas

a violência é um aspecto extremamente perverso destas, já que corresponde à anulação da relação entre dois sujeitos e a redução de um dos pólos da relação a simples objeto $^{(10)}$.

A sexualidade vivida de forma paradoxal e opressora traz em si diversos elementos de violência, inclusive aqueles que Bourdieu denomina violência simbólica, violência insensivel e violência invisível ${ }^{(11)}$.

Esses tipos de violência não atingem apenas o corpo, mas também a dignidade da pessoa humana, sujeitando a mulher à dominação do violentador.

\section{Procedimentos metodológicos}

A pesquisa foi realizada com 10 profissionais integrantes de equipes de Saúde da Família de regiões próximas a Belo Horizonte, que conformaram um grupo de trabalho composto por quatro agentes comunitários de saúde, um auxiliar de enfermagem, dois enfermeiros e três médicos. As categorias profissionais foram compostas por homens e mulheres. A coleta de dados foi realizada durante duas sessões de Oficina de Trabalho, com duração aproximada de 6 horas, distribuídas em dois períodos de 3 horas cada um. Para a realização da segunda parte da oficina, foi utilizada uma narrativa que os participantes elaboraram no primeiro dia sobre uma situação de violência sexual que haviam testemunhado no trabalho. Dentre os casos escritos, foram selecionados dois para serem trabalhados pela técnica de dramatização e, posteriormente, discutidos e analisados.
A análise dos dados coletados nas oficinas foi baseada nos elementos dos pressupostos teóricos e metodológicos ${ }^{(12-13)}$.

\section{Aspectos éticos}

O projeto foi apreciado pelo Comitê de Ética em Pesquisa da Escola de Enfermagem da Universidade de São Paulo (Parecer n. 386/2004) e aprovado em 13 de setembro de 2004. Por motivos éticos, no texto, os locais de trabalho e os nomes dos sujeitos foram mudados. Atendendo a resolução 196 de outubro de 1996, do Conselho Nacional de Saúde, foi solicitada aos participantes a assinatura de um Termo de Livre Consentimento, em duas vias, uma das quais permaneceu com eles e outra com a pesquisadora.

\section{RESULTADOS E DISCUSSÃO}

Para preparar a reflexão específica acerca das práticas voltadas para mulheres em situação de violência sexual, a primeira sessão da oficina abordou o tema Homem e mulher no mesmo barco social, com os objetivos de: 1) explicitar e analisar a visão de mulher e de homem dos membros da equipe de saúde da família; 2) refletir sobre o processo de construção da masculinidade e da feminilidade na sociedade brasileira.

A seguir, a reflexão acerca das práticas foi feita a partir da dramatização dos dois casos escolhidos. O caso 1 descreveu a história de uma mulher jovem, adulta, casada, com filhos, que foi estuprada ao retornar do trabalho, sob a ameaça de um revólver. Depois disso, ela voltou para casa e foi ao Centro de Saúde para procurar a ajuda dos profissionais do PSF. No início, não falou nada acerca da violência sofrida e a sua principal queixa era insônia. Só depois é que detalhou a situação toda. No caso 2 são relatados fatos ocorridos com uma menina que vivia em situação de violência sexual dos 9 aos 13 anos de idade. Ela foi levada pela mãe ao Centro de Saúde, com queixa de verminose, escondendo uma gravidez. Na consulta, a criança relatou que o próprio pai era o violentador.

No momento da oficina, os sujeitos dividiram-se em dois grupos para organizar as dramatizações, mesclando os municípios de origem e as categorias profissionais. As duas situações foram apresentadas seqüencialmente, de forma rica e criativa. $O$ conflito emergiu da relação entre os personagens atuando em um pequeno espaço e tempo limitado. Durante a encenação, o que parecia desordem era apenas algo externo, pois no conjunto da apresentação havia plasticidade e o imperativo de dar ao texto uma ordem quase real, exigida pela estética da arte. Foi uma atividade cênica que gerou um material rico e diversificado para o trabalho científico, evidenciando as características do ato criador: a espontaneidade, o inesperado e a realidade ${ }^{(14)}$.

Após as encenações, iniciou-se o debate sobre os dois casos, com os participantes discorrendo sobre o que sentiram e perceberam ao interpretar as diversas personagens. A análise das suas falas possibilitou a emergência de quatro categorias empíricas, descritas e analisadas a seguir. 


\section{A relação entre o silêncio da mulher e a impotência do profissional de saúde}

Marília disse que se sentiu impotente diante do caso. No grupo surgiu um movimento interno de afasia, revelando certa perda de poder de expressão verbal ao transitar pelo tema proposto. Ester relata que quando atendeu a mulher, na vida real, percebia que ela estava com problemas, pois já havia passado por diversos profissionais do Centro de saúde e ninguém havia resolvido o seu problema. Ela também, como médica, não conseguiu resolver, pois a consulta ficou só no sono e no efeito da medicação.

Carlos relata ter percebido, ao longo de vários meses de atendimento, que algumas mulheres teriam algo mais a dizer, além das queixas que traziam. Afirmou que procurou colegas mais antigos da equipe de Saúde da Família e preparou-se para ficar mais atento. Entretanto, ainda hoje, quando as mulheres relatam abuso sexual fico perdido, sem fala, diz ele.

Pode-se perceber pelos discursos que os dois profissionais tentaram resolver o caso individualmente, na singularidade do atendimento e do serviço, sem arti-culá-lo às demais dimensões da realidade obje-tiva, quais sejam, a particular e a estrutural.

Sabe-se que é bastante difícil e, até certo ponto impossível, resolver um problema somente na singularidade ou no nível da atenção básica. Fica constatada a necessidade de discutir a questão de violência contra as mulheres na cotidianidade dos serviços de saúde, de definir prioridades para capacitar os profissionais e de estabelecer parcerias com outros serviços, considerando que a violência sexual contra a mulher exige abordagem e intervenção interdisciplinares e intersetoriais.

Como os profissionais, em geral, continuam tentando solucionar o problema individualmente, o medo da violência aparece de forma bem clara no discurso de Tomás, quando comenta a intervenção policial no Centro de Saúde: Pensei na proteção do profissional e questionei por que os médicos e enfermeiros estão entrando nisso.

Tal posição indica o receio que o profissional sente ao atuar quando o assunto é violência contra a mulher. Aparentemente a estrutura do serviço não tem um setor organizado para esse trabalho, tanto preventivo como curativo. A atitude do profissional acaba sendo de afastamento ou negação.

No primeiro caso narrado, há uma ordem expressa, sob ameaça de morte, revelada na seguinte frase: Se gritar eu mato.

Também no segundo caso, havia uma ordem do pai exigindo silêncio. A criança que viveu em situação de violência sexual desde os 9 anos de idade, dentro da própria casa, disse que era ameaçada se falasse para alguém.
No primeiro caso, a mulher nada relatou para o marido, não fez denúncia policial, não falou para a recepção do Centro de Saúde, expressando-se somente um tempo depois, com dificuldade, para a médica.

A menina violentada dos 9 aos 13 anos tipifica a violência sexual contra as mulheres em diversas sociedades e culturas. Em um estudo sobre abusos sexuais com crianças (na maioria, meninas), destaca-se o segredo e o silêncio, durante a síndrome de adaptação no momento pós-traumático ${ }^{(15)}$. Além da violência física, há o momento da descoberta como um trauma para a criança, pois as ameaças tornam os efeitos da revelação ainda mais perigosos que o próprio ato.

A criança nunca diz nada, ela teme a punição ou a incapacidade dos adultos de protegê-la da violência e de seu agressor ${ }^{(15)}$.

A despeito de localizarem predominantemente a violência contra a mulher na dimensão singular, os sujeitos da pesquisa também expressaram que ela faz parte da engrenagem social. Quando se faz essa leitura, há possibilidade de compreender como a violência sexual contra a mulher está diretamente ligada ao poder dos homens sobre as mulheres.

Nesse sentido é que se pode tentar relacionar o silêncio imposto às mulheres em situação de violência sexual com a impotência manifestada pelos profissionais de saúde nesta oficina. Tanto o silêncio como a impotência, tem o medo como um dos elementos paralisantes. O medo da mulher e do profissional de saúde tem uma fonte comum, que é a dominação masculina. Tocar no poder do homem violento carrega na mesma esteira a apreensão da mulher que sofreu violência sexual no velho galpão, da menina em relação ao pai, a da mãe da menina que convive com a realidade e não consegue denunciá-la e a dos profissionais de saúde que atuam na atenção básica.

Davi revela que ficou surpreso ao constatar como a mulher sofre profundamente calada, sem perceber que o silêncio pode ser revelador do medo, da vergonha e da submissão. Não é difícil verificar que as categorias sociais subalternas são, no Brasil, constituídas por mulheres, negros, pobres e crianças ${ }^{(16)}$. Nessa hierarquia, o último lugar é ocupado pela mulher negra, pobre e criança. No topo dessa escala de poder está o macho branco, rico e adulto. O poder do homem adulto sobre a mulher, reconhecido socialmente, motiva o silêncio da mulher e pode motivar a impotência do profissional de saúde. Em outras palavras, os diversos silêncios - da mulher que sofre a violência sexual, da mãe, da família, da comunidade e dos profissionais de saúde - têm várias causas, mas há um ponto comum que liga todos estes sujeitos: o poder do homem. O poder como prática social, historicamente constituída, que não aparece como algo grande, que reprime, que assusta. Chama a atenção para o micropoder nos diversos espaços, exercido em rede ${ }^{(17)}$. 
O micropoder aparece no caso da Cristiane, a menina engravidada pelo pai. Tomás relata que a mãe saía, catava papéis e depois tomava medicamento para dormir. O pai comandava a situação.

Um estudo diz também que os homens investem muitos esforços para preservar o seu poder ${ }^{(16)}$. Há hierarquia entre o poder adulto e a criança, indivíduos de gerações diferentes. No movimento da transversalidade, que é própria da violência de gênero, nesse caso há o cruzamento das categorias gênero e geração. $\mathrm{O}$ agressor detém pequenas parcelas de poder, sem deixar de aspirar ao grande poder. O pai apresenta a síndrome do pequeno poder. $\mathrm{O}$ homem detentor do pequeno poder crê ser necessário exercitar-se, a fim de, algum dia, vir a encarnar plenamente a figura do macho poderoso $^{(16)}$. Na dramatização foi mostrado que Cristiane era submissa ao pai e colocada na posição de objeto na situação, levando-a a manter-se em silêncio até o início da gravidez, quando tornou-se impossível esconder a situação.

Fernando chama a atenção para o silêncio e a impotência da mãe comparando-o com um caso que acompanhou na área rural do seu município: Ficou claro que a mãe tinha consciência... a porta ficava semi-aberta e ela sempre acompanhava aquilo... é uma questão de impotência da mãe. $\mathrm{O}$ problema é que, como profissional de saúde, não sabia o que fazer naquela situação.

Quanto mais dominada for a mulher, mais difícil lhe será reunir as forças necessárias para proteger as suas filhas. Algumas denunciam o marido, mas falta-lhes coragem para sustentar a denúncia. Por isto, como resultado, há anos de convivência com o incesto pai-filha ou padrasto-enteada ${ }^{(16)}$.

Ester diz que a mãe precisava de mais ajuda, porque ela teria tido o poder de mudar a história, se fosse claramente instruída sobre o fortalecimento dela e da existência das leis. Ela considera que $A$ mãe está num contexto e não tem recursos para sair. Mas faltou um profissional para dizer a ela que isto pode mudar.

\section{A importância da escuta na prática dos profissionais}

Os dois casos mostraram que, ao procurarem o serviço, as mulheres tinham um discurso indireto, reticente e enfocando outras queixas. No primeiro caso, a insônia e, no segundo, verminose, dois sintomas que poderiam perfeitamente passar ao largo da violência sexual. Tais fatos dificultaram o atendimento imediato.

Carlos revela que fez um grande esforço para desenvolver a capacidade de assistir as mulheres em situação de violência sexual no trabalho. Percebia algo oculto, não dito, por parte de algumas mulheres, porém, não conseguia descobrir de que se tratava. Para tanto, procurou ajuda de uma pessoa mais experiente, que lhe sugeriu dar mais tempo para as mulheres se expressarem. A partir daí foi estabelecendo articulações entre alguns elementos trazidos pelas mulheres, relacionados às diversas queixas diversas e começou exercitar o ato da escuta. Ao começar a escutar as poliqueixosas, percebeu que algumas mulheres estavam sendo violentadas. Não necessariamente que todas tivessem sofrido violência sexual, mas observou que queixas variadas advindas de uma mesma mulher poderiam ser um indicativo importante da presença do fenômeno.

Durante a oficina, o grupo considerou a verbalização desse problema é difícil porque ela permeada de incertezas, culpa, vergonha, medo de não ser compreendida, medo de se expor e medo quanto à segurança pessoal. Um estudo realizado em São Paulo considera que a denúncia de crime sexual, até o presente momento, encontra diversas barreiras sociais, jurídicas e emocionais. No Brasil, a maior parte das mulheres não registra queixa por constrangimento e medo de humilhação, somado ao receio de falta de compreensão ou interpretação dos familiares, amigos, vizinhos e autoridades ${ }^{(18)}$. Outros estudos mostram ainda que nas delegacias comuns, ao invés de atender, os profissionais julgam a mulher para saber se ela mereceu ou não sofrer violência. Muitas vezes ela é motivo de riso, de gracejos de mau gosto, é julgada e até assediada ${ }^{(19)}$.

A atenção básica de saúde pode vir a ser uma eficaz porta de entrada para a mulher que está vivendo relações violentas de gênero, em especial de violência sexual. Alguns estudos dão conta de que os serviços de saúde têm sido escolhidos pelas mulheres para relatar a situação de violência sexual em que vivem. Neste caso, adota-se o acolhimento que

é uma postura de escuta, compromisso de dar uma resposta às necessidades de saúde trazidas pelo usuário e um novo modo de organizar o processo de trabalho(20).

Ao abordar a violência sexual, o Ministério da Saúde reconhece que os profissionais não estão preparados para prestar assistência às mulheres e a maioria dos serviços de saúde não está equipada para diagnosticar, tratar e contribuir para a prevenção da sua ocorrência ${ }^{(21)}$.

A menina Cristiane permaneceu em situação de violência sexual invisível durante quatro anos. Ela freqüentava escola do município, estava na área de abrangência de um serviço de saúde e nenhuma das instituições sequer identificou a violência, referendando que a sociedade convive silenciosamente com tais situações. Silêncios e invisibilidades são também questões de gênero e de violência de gênero.

São realidades que podem e devem ser abordadas no plano psicoemocional, sóciocultural e ético-político para uma aproximação primeira de sua complexidade ${ }^{(22)}$.

O acolhimento dessas mulheres só poderá ser realizado se o profissional levar em conta que para elas

as emoções, a soberania, a dignidade e o direito estão corrompidos e negados, e que, na saúde ou em outros 
âmbitos da vida social, devem motivar os estudos e as políticas de assistência(22).

\section{Compreendendo a passagem do natural para o cultural}

Foram também feitos alguns questionamentos sobre a gênese da violência sexual contra a mulher, na tentativa de compreender por que ela ocorre com tanta naturalidade. Davi considera que as mulheres podem se acostumar com essas atitudes, uma vez que já aconteceram em gerações passadas. As meninas podem considerar tudo natural $e$ continuar sendo propriedade passiva para uso do pai, do padrasto, do vizinho etc. Há um risco, pois existem meninas que acham que isto é comum, que a vida é assim mesmo e que sempre foi assim.

Fernando comenta a seqüência da construção cultural deste modelo: A mãe já se acostumou e pode ter tido a mesma história de violência sexual na sua infância. Revela assim, a compreensão de que a violência sexual é natural, imutável, passa de geração em geração. Muitas mães foram vítimas dos pais no passado e agora elas ficam se vendo quando a filha sofre violência do pai.

Raquel acrescenta que $O$ pai pode praticar violência sexual com todas as filhas da casa e isto é natural.

Ocorre, que a passagem do natural para o cultural foi construída lentamente pela humanidade. A formação histórica da família mostrou um grande esforço da humanidade para conseguir a ruptura com o incesto. Foi um corte que provocou grande desconforto no ser humano, de forma integral. E o processo é irreversível, pois não há como o humano voltar a ser somente natureza. Se tal proibição é necessária à constituição da família é porque, além do primado natural induzido pela diferença sexual, intervém uma outra ordem da realidade que, desta vez, não deriva de um fundamento biológico. A proibição do incesto é, portanto, tão necessária à criação da família, quanto a união de um macho com uma fêmea ${ }^{(23)}$.

Tal construção está ligada ao simbólico e proíbe os diversos incestos, em vários graus. A civilização sempre provocou grandes sacrifícios para a humanidade, no que diz respeito não somente à sexualidade, mas também à agressividade. Isso significa que o ser humano negociou uma parte de seu gozo pela segurança e pela cultura. A mulher não ficou em boa posição nessa troca. O ser humano civilizado trocou uma parcela de suas possibilidades de gozo, por uma parcela de segurança. Contudo, na família primeva apenas o chefe desfrutava da liberdade pulsional, os demais viviam em opressão servil ${ }^{(24)}$.

Como a sociedade encontra-se em constante transformação, é necessário fazer as intervenções para que o processo não fique estagnado. A cultura é uma construção histórica do ser humano, mas ela impõe algo que é muito con- creto para o sujeito: ele fica distanciado de sua origem animal por meio da linguagem. Na passagem do natural para o cultural, já que o fundamento da civilização reside na maleabilidade das pulsões perversas, devemos esperar que o meio social se esforce ao máximo para encaminhar essas pulsões a fins culturais, obstruindo com isto as manifestações não concordantes com o que visa ${ }^{(25)}$.

\section{Repensar o trabalho para potencializar para novas}

Fizeram parte da categoria em tela a potencialização do poder da mulher e do profissional de saúde no processo de trabalho. Os debates e as análises moveram-se na busca de novos caminhos e a oficina de trabalho desenvolvida foi vista como um instrumento privilegiado para a qualificação profissional quanto ao tema.

Potencialização foi entendida como o processo de reconhecimento daquilo que afeta a capacidade de ter acesso ao poder, de forma a transformar a sua realidade. $\mathrm{O}$ enfoque fundamenta-se na compreensão de saúde relacionada a um conjunto de valores, tais como: solidariedade, cidadania, participação, subjetividade e revalorização ética da vida ${ }^{(26)}$. No contexto da promoção da saúde e da prevenção da violência sexual, uma das principais ações está relacionada à potencialização das mulheres e dos profissionais de saúde.

Marília disse que após a oficina sentia-se respaldada para poder falar à vontade sobre o tema violência sexual e que a palavra para ela foi libertadora. Ela se sentiu mais forte e livre dentro do grupo, ressaltando que o discurso coletivo abriu a possibilidade da reflexão, em que os participantes puderam manifestar tanto a impotência no início dos trabalhos quanto a potencialização. Reconhecer a impotência, nesta pesquisa, foi um grande passo para a potencialização.

Ester expressou esse efeito dizendo que antes não sabia trabalhar com a problemática de violência sexual contra a mulher e na oficina teve oportunidade de escutar opiniões diferentes dos profissionais médico e outros profissionais da equipe do PSF, mostrando não estar sozinha nisto.

Carlos disse que há uma tendência a imaginar que se está num país das maravilhas mas a violência e a questão de gênero existem. Para ele, é preciso começar a fazer alguma coisa para mudar um pouco a história dessas mulheres.

Os discursos deixaram claro que é preciso um movimento por parte dos profissionais para sair da impotência e se tornarem novos agentes de mudança social, capazes de dar uma direção para as mulheres que vivem em situação de violência sexual.

Francisco fez uma síntese do que vivenciou no grupo, mostrando o potencial da oficina ao discutir violência sexual contra a mulher. Considerou-se privilegiado por estar participando dessa pesquisa por estar tendo oportunidade de 
sair da impotência. Para ele, a oficina pode contribuir para a qualificação dos profissionais acerca do tema.

Concordando com a idéia de potencialização, Raquel e Marília avaliaram que a violência sexual deve ser denunciada e, além disso, o homem - ator da violência - também deve ser tratado. Basearam-se no reconhecimento de que o agressor também é produto da sociedade e precisa ser assistido para poder viver nela.

Além disso, o grupo reconheceu que a ação profissional individual sem preparo específico é precária e limitante, pois vem mesclada pelo medo e regida pelo velho adágio popular em briga de marido e mulher não se mete a colher. Se assim for, os profissionais podem estar sendo coniventes com a continuidade da violência sexual contra a mulher.

Quando numa cidade os cidadãos não tomam das armas porque estão aterrados pelo medo, não se pode dizer que aí exista paz e sim mera ausência de guerra. A paz não é pura ausência de guerra, mas virtude originada da força da alma para respeitar as leis ${ }^{(27)}$. Durante a fase inicial do combate, em lugar de lutar pela liberdade, pode ser que os oprimidos tendam a converter-se, eles mesmos, em opressores. A própria estrutura do seu pensamento pode estar condicionada pelas contradições da situação existencial concreta que os manipulou. É possível que os oprimidos, num dado momento de sua experiência existencial, adotem uma atitude de adesão em relação ao opressor ${ }^{(28)}$.

Marília nomeia um elenco de ações que existem no âmbito do Programa de Saúde da Família, em que se pode atuar na promoção da saúde e esclarecer dúvidas e potencializar as mulheres, tais como: reflexões em grupos, visitas domiciliárias e consultas individuais. Na oficina, os profissionais mostraram algumas saídas para o impasse. Mesmo reconhecendo as dificuldades, continuam a buscar formas de prática que respondam, pelo menos, em parte aos problemas.

A noção de potencialização individual e coletiva é importante tanto para os profissionais de saúde da família como para as mulheres em situação de violência sexual: os profissionais, para terem mais segurança nos procedimentos e as mulheres, para saírem da situação de medo, de culpa e fragilidade.

Se o Estado deve investir no estrutural, na singularidade dos serviços é preciso fazer parcerias com os demais equipamentos sociais (escolas, associações de bairro, igrejas, polícia, delegacias de mulheres, abrigos e outras formas de organização) para o enfrentamento da complexidade da violência sexual.

O Programa de Saúde da Família traz no seu elenco de propostas trabalhar com a promoção da saúde, portanto, o problema em pauta deve ser encarado também nas ações de vigilância em saúde. Diante do tema violência sexual contra a mulher, ao mesmo tempo em que se preparam para atender pessoas acometidas com este mal, os profissionais podem preparar-se também para trabalhar com a prevenção.
Sintetizando, Davi fala acerca da importância de repensar o trabalho das equipes de Saúde da Família para potencializar novas práticas:

Essa experiência de deslocamento, de possibilidade de colocar-me na situação da mulher, sendo homem, foi bastante rica. Saio daqui com alguma coisa [...] Essa opção é um salto. Eu tive que mudar a consciência de mundo [...] as mulheres prá mim hoje têm uma diferença muito grande.

\section{CONCLUSÃO}

A pesquisa evidenciou que ao analisar problemas que incidem sobre a mulher é importante considerar o estudo do homem e da mulher, pois é nas relações entre ambos que podem ser identificados os problemas de gênero. No caso da violência sexual contra a mulher é preciso considerá-lo como um amplo problema social onde homens e mulheres se encontram e se confrontam com suas diferenças. A violência sexual contra a mulher no espaço doméstico está diretamente ligada ao modelo social das relações de dominação histórica do homem sobre a mulher.

Quanto ao conhecimento de gênero interferindo nas relações homem-mulher e no atendimento de saúde, poucos componentes do grupo mostraram ter familiaridade com o tema. Constatou-se a formação dos profissionais ali presentes, seja de nível médio ou superior trazia a marca do mundo organizado sob a égide do poder masculino. Os estereótipos revelados mostraram que as formas de ser e estar no mundo, quer dos homens, quer das mulheres, traziam também as marcas de arranjos sociais que dificultam a construção de novas práticas e novas relações no trabalho em equipe e junto aos usuários e usuárias dos serviços de saúde. Na pesquisa, ainda, foi possível identificar elementos da macro-estrutura que determinam as formas de pensar dos profissionais, cuja transformação depende de um movimento permanente de reflexão sobre o tema. As dificuldades em atender mulheres em situação de violência sexual expressam o quanto a ciência é construída e disseminada nas escolas numa perspectiva masculina, onde a mulher continua sendo invisível tanto no processo de produção como de reprodução social.

Os profissionais consideraram que a sua atuação é caracterizada por uma impotência paralisante que pode ser atribuída à falta de preparo, de organização do processo de trabalho e aos valores sociais que são absorvidos de forma sutil através da história de vida de cada sujeito e do grupo como um todo. Ao atenderem mulheres em situação de violência sexual os profissionais que integram as equipes de saúde da família definem sua atuação como de impotência paralisante que consideram como um reflexo da falta de organização do serviço para este fim.

De outro lado, constatou-se falta de concretização das Políticas Públicas que incluam e organizem ações conjuntas da Polícia Militar, Ministério Público, Secretaria Estadual de Defesa Social, Secretaria de Educação e Defesa Social. Nos 
níveis central e estadual há leis e documentos para assistir a mulher em situação de violência sexual, mas o nível local ainda carece de apoio concreto para atuação dos profissionais.

As idéias de reorientação da prática que surgiram durante a oficina estão ligadas a questões referidas à intersetorialidade, interdisciplinaridade e à integralidade.

Ainda, a oficina mostrou constituir-se em uma excelente estratégia pedagógica para preparar os profissionais dada a maneira como foi avaliada. As pessoas se sentiram efetivamente participantes e dotadas de poder para ampliar o conhecimento sobre suas vidas e sua prática.

É indispensável considerar o papel esperado dos profissionais das equipes do Programa de Saúde da Familia, na construção de novas maneiras de pensar e fazer que superem as modalidades assistenciais marcadas por concepções biologicistas, focadas no individual e na medicalização.

As falas captadas e analisadas não significam nem o começo nem o ponto final de tudo o que tem a ser dito sobre as práticas dos profissionais do PSF sobre violência sexual contra a mulher. A pesquisa foi um espaço temporal do trabalho, onde os profissionais de saúde puderam manifestar, através da linguagem, a ideologia que perpassa a sua prática. Como a condição da linguagem é a incompletude, podemos considerar que esta contribuição é uma parcela que nos leva a pensar sobre a importância da potencialização dos profissionais de saúde da atenção básica.

\section{REFERÊNCIAS}

1. Organização Mundial da Saúde (OMS). Relatório Mundial sobre Violência e Saúde. Genebra; 2002.

2. Saffioti HIB. Violência de gênero: poder e impotência. Rio de Janeiro: Revinter; 1995.

3. Cook RJ. La santé des femmes et les droit de l'individu: la promoción et la protection de la santé des femmes par le droit international relatif aux droits de l'homme. Genève: OMS; 1995.

4. Rosas CF. Atendimento à mulher vitimada sexualmente. In: Ipas Brasil [home page na Internet]. Rio de Janeiro; 2003. [citado 2003 nov. 15]. Disponível em: http://www.ipas.org.br/arquivos

5. Ipas Brasil. Violência sexual contra a mulher. Projeto Brasil, 2003 [home page na Internet]. Rio de Janeiro; 2003. [citado 2003 nov. 17]. Disponível em: http://www.ipas.org.br/violencia. htm

6. Minayo MCS. O desafio do conhecimento: pesquisa qualitativa em saúde. $6^{\text {a }}$ ed. São Paulo: Hucitec; 1999.

7. Pandjiarjian V. Os estereótipos de gênero nos processos judiciais e a violência contra a mulher na legislação. In: Ipas Brasil [home page na Internet]. Rio de Janeiro; 2003. [citado 2003 nov. 18]. Disponível em: http:// www.ipas.org.br/arquivos

8. Fonseca RMGS. Equidade de gênero e saúde das mulheres. Rev Esc Enferm USP. 2005;39(4):450-9.

9. Scott J. Gênero: uma categoria útil para a análise histórica. Trad. de Christine Rufino Dabat e Maria Betânia Ávila. $2^{\mathrm{a}}$ ed. Recife: SOS Corpo; 1995. p. 1-11

10. D’Oliveira AFPL, Schraiber LB. Violência de gênero, saúde reprodutiva e serviços. In: Giffin K, Costa SH. Questões da saúde reprodutiva. Rio de Janeiro: FIOCRUZ; 1999. p. 342.

11. Bourdieu P. A dominação masculina. $3^{\mathrm{a}} \mathrm{ed}$. Rio de Janeiro: Bertrand Brasil; 2003.

12. Minayo MCS organizadora. Pesquisa social: teoria, método e criatividade. $22^{\mathrm{a}}$ ed.Petrópolis: Vozes; 2003.

13. Bourdieu P, coordenador. A miséria do mundo. $5^{\mathrm{a}}$ ed. Petrópolis: Vozes; 2003.

14. Moreno JL. Psicodrama. $9^{a}$ ed. São Paulo: Cultrix; 2003.
15. Lamour M. Os abusos sexuais. In: Gabel M. Crianças vítimas de abuso sexual. São Paulo: Summus; 1997.

16. Saffioti HIB. A síndrome do pequeno poder. In: Goldberg MAA, Guerra VNA, organizadoras. Crianças vitimizadas: a síndrome do pequeno poder. São Paulo: Iglu; 1989. p. 16-21.

17. Foucault M. Microfísica do poder. $6^{\mathrm{a}}$ ed. Rio de Janeiro: Graal; 1986.

18. Drezett J, Baldacini I, Freitas GC, Pinotti JA. Contracepção de emergência para mulheres vítimas de estupro. Rev Centro Referência São Paulo; 1998;(3):29-33.

19. Jurema SB. [Entrevista com a Presidente do Conselho Nacional dos Direitos da Mulher]. Rev Promoção Saúde Mulher Bras. 2002;6(83):11.

20. Merhy EE. Acolhimento: uma reconfiguração do processo de trabalho em saúde. In: Brasil. Ministério da Saúde. Sistema Único de Saúde em Belo Horizonte. São Paulo: Xamã; 1998. p. 139.

21. Brasil. Ministério da Saúde. Secretaria de Políticas Públicas. Coordenadoria Nacional DST/HIV/AIDS. Programa Saúde da Mulher. Norma Técnica. Prevenção e tratamento dos agravos resultantes da violência sexual contra mulheres e adolescentes. Brasília; 2002.

22. Schraiber L, D’Oliveira AF, Hanada H, Figueiredo W, Couto M, Kiss L et al. Violência vivida: a dor que não tem nome. Interface Comun Saúde Educ. 2003;7(12):41-54.

23. Roudinesco E. A família em desordem. Rio de Janeiro: Zahar; 2003.

24. Freud S. Obras psicológicas completas de Sigmundo Freud. edição standart brasileira. Rio de Janeiro: Imago; 1974. O mal estar da civilização; v. 21.

25. Millot C. Freud antipedagogo. Rio de Janeiro: Zahar; 1987.

26. Martins Júnior T. Apoderamento. SANARE. 2003;4(1):14-7.

27. Espinosa B. Tratado político. $2^{\mathrm{a}}$ ed. Lisboa: Editorial Estampa; 1977.

28. Freire P. Conscientização: teoria e prática da libertação. $3^{\mathrm{a}}$ ed. São Paulo: Moraes; 1980.
Correspondência: Celina Camilo de Oliveira Rua Jornalista Waldir Lau, 384 CEP 31710-560 - Belo Horizonte, MG, Brasil 